\title{
Intrauterine Device in the Immediate Postpartum: Study Comparing Insertion after Cesarean Section and Vaginal Delivery
}

\author{
Moussa Diallo1, Hadja Maïmouna Barro Daff ${ }^{*}$, Abdoul Aziz Diouf' , Aminata Niass', \\ Youssou Toure' ${ }^{2}$, Khalifa Fall'2, Alassane Diouf ${ }^{1}$ \\ ${ }^{1}$ Departement of Obstetrics and Gynecology, Pikine University Hospital, Thiaroye Pikine, Sénégal \\ ${ }^{2}$ Cheikh Anta Diop University of Dakar, Gynecological and Obsetric Clinic, Public Institution Aristide-Le Dantec Health Center, \\ Dakar, Senegal \\ Email: ^hmbdaff@gmail.com
}

How to cite this paper: Diallo, M., Daff, H.M.B., Diouf, A.Z., Niass, A., Toure, Y., Fall, K. and Diouf, A. (2019) Intrauterine Device in the Immediate Postpartum: Study Comparing Insertion after Cesarean Section and Vaginal Delivery. Open Journal of Obstetrics and Gynecology, 9, 1510-1518. https://doi.org/10.4236/ojog.2019.911146

Received: October 8, 2019

Accepted: November 16, 2019

Published: November 19, 2019

Copyright $\odot 2019$ by author(s) and Scientific Research Publishing Inc. This work is licensed under the Creative Commons Attribution International License (CC BY 4.0).

http://creativecommons.org/licenses/by/4.0/

(c) (i) Open Access

\begin{abstract}
Objective To compare the safety, side effects and failure rates of contraception copper intrauterine device (IUDs) in the immediate postpartum period after a vaginal delivery and during a cesarean section. Patients and methods This was a descriptive and analytical study, conducted in Gynecology and Obstetrics departments hospital Pikine and Abass Ndao hospitals. It compared two groups of women with IUDs in the immediate postpartum period after a vaginal delivery and during cesarean section. Our sample consisted of 215 patients. We had divided them into two groups: group 1 consisted of 115 patients who delivered by cesarean section; Group 2 consisted of 100 patients who delivered vaginally and whom the insertion was made in post placental or within 48 hours after birth. The variables studied were the sociodémographic characteristics, characteristics of pregnancy and childbirth, insertion procedures, follow up with the assessment of side effects and complications. Results and comments The socio-demographic characteristics were superimposed in both groups. Nine patients were lost to follow up, 4 in group 1 and 5 in group 2 . The complaints such as pain (3.7\% for Group 1 against $2.6 \%$ for group 2 ), vaginal bleeding (2.1\% for group 2 , and $1.8 \%$ for group 1 ) were rarely reported and stackable in both groups. After 6 months of follow up, the menses was observed in $42.8 \%$ of group 2 against $43.1 \%$ of group 1 . The abnormal menstrual flow, evaluated by the Higham score, was noted in $29.6 \%$ of group 2 and $25 \%$ of group 1, and was dominated by excessive bleeding. They motivated IUD removal in two patients. A significant difference was found in the perception of IUD strings, it was effective in $95.4 \%$ of patients in group 2 against $50.5 \%$ for group 1 . The evictions were 9 at 3-month follow-up 7 related group 2 and 2 for Group 1. It was partial (isth-
\end{abstract}


mic IUD) and total expulsion. At 6 months follow-up, 3 cases of partial expulsion were noted and concerned only group 2 . This made a total expulsion rate of $5.3 \%$, with $9.5 \%$ for group 2 , and $1.8 \%$ for group 1 . no cases of pregnancy or uterine perforation had been reported during this study. A vaginal sampling was performed in all our patients and the results were generally comparable in both groups and normal in most cases. However, we noted $17.6 \%$ of infection in group 2, and $16.2 \%$ in group 1. Conclusion From the results of our study, we can say that IUD insertion in the period of immediate postpartum remains safe and effective regardless of the way of delivery. The risk of expulsion is minimal so acceptable.

\section{Keywords}

Copper IUDs, Postpartum, Postplacental, Childbirth, Cesarean Section, Vaginal Delevery

\section{Introduction}

For most women the contraceptive desire is felt just after delivery but only $40 \%$ of them will resort to contraceptive methods [1]. Unmet needs especially during this period therefore remain alarming and have a direct impact on maternal and child health. Indeed pregnancies occurring in the first year after childbirth are the most dangerous for the mother and child due to an increased risk of complications. In Senegal, contraceptive prevalence (CP) increased progressively from $8 \%$ to $25 \%$ for all methods between 1997 and 2016 [2]. However, this increase remains below expectations in line with the national family planning strategy 2016-2020. Increasing the contraceptive prevalence, the reduction of maternal and infant mortality involves the use of modern methods of long-term contraception such as the intrauterine device (IUD). The best time to deliver this contraception remains postpartum. Indeed, the need for contraception is the highest and clients are in contact with health care providers. IUD used in the postpartum several advantages. Indeed it is a method of safe and reversible long-term, highly effective with a Pearl Index of around $0.1 \%$ and does not interfere with breastfeeding [3]. It is also relatively cheap, convenient and has a very low complication rate [1]. In literature, the IUD inserted into the period of the immediate postpartum period is associated with an expulsion rate much higher than for the interval IUD [4].

The objectives of our study were to demonstrate the efficacy and safety of IUD insertion in the immediate postpartum regardless of the route of delivery, identify and compare the side effects and possible complications in both delivery route.

\section{Patients and Methods}

It was a prospective, descriptive, analytical and comparative study conducted at 
the Departement of Obstetrics and Gynecology at Pikine National Hospital and Abass Ndao Hospital Centers from January $1^{\text {st }} 2016$ to $31^{\text {st }}$ July 2018.

The study population consisted of 215 patients divided into two groups.

- Group 1 consisted of patients who delivery by caesarean section and had the IUD inserted during the procedure.

- Group 2 corresponded to patients who delivered vaginally and had the IUD inserted in postplacental or immediate postpartum.

We have included in our cohort all patients who had delivered in these two departements, had received counseling for postpartum contraception and had accepted the method.

Excluded where those with membrane rupture for more than 12 hours, amniotic infection proven, history of ectopic pregnancy or pelvic inflammatory disease (PID), multiple uterine scars or postpartum haemorrhage (PPH).

Patients were recruited during prénatal consultations, during hospitalization or even in the delivery room. An oriented contraceptive counseling for the method was then performed. The advantages and limitations of the method were made clear to patients.

The IUD chosen was the TCu $380 \mathrm{~A}$.

Manual or instrumental insertion was performed during caesarean section or after vaginal delivery.

An ultrasound was subsequently conducted by a senior before hospital discharge to ensure the correct positioning of the IUD. The distance between the horizontal leg of the IUD and the uterine fundus and the bottom of the uterine cavity was measured in millimeters $(\mathrm{mm})$. Patients were seen at three and six months. During these visits, a routine gynecological examination was performed and a pelvic ultrasound to ensure the correct position of the IUD with measuring distances mentioned above.

Adverse effects and usual complications such as pain, bleeding, vaginal discharge, pregnancy, migration or expulsion of the IUD were sought. A vaginal sample was taken at 6 months of follw-up in seach of possible infection.

Statistical analysis was performed using Excel software and SPSS for windows 23 version for mac.

\section{Results}

Two hundred fifteen (215) patients had received insertion of copper IUD in the postpartum period. Forty-six point five percent $(46.5 \%)$ of these insertions were made after vaginal delivery and $53.5 \%$ were made per-ceasarean.

\subsection{Sociodemographic Characteristics}

The sociodemographic characteristics were similar in both groups (Table 1). The average age of patients was 30 years for Group 1 against 28 for group 2. They were married for most part, unemployed and resided in Dakar suburb.

Nine patients, 4 in Group 1 and 5 in Group 2 were lost to follow-up (4.2\%), 
the remaining patients had honored monitoring visits. There was no significant difference in terms of lost compared to the delivery route $(p=0.886)$.

\subsection{Location of the IUD}

After an ultrasound control, all IUDs were in place.

Mean distance between the fundus and the IUD (Fundus-IUD) and between the cavity and the IUD (Cavity-IUD) were respectively $29 \mathrm{~mm}$ and $3.7 \mathrm{~mm}$ for the vaginal delivery.

Table 1. Characteristics of the study population.

\begin{tabular}{|c|c|c|c|}
\hline Characteristics & Group 1 & Group 2 & \\
\hline Age & 28 years old & 30 years & $P=0.936$ \\
\hline \multicolumn{4}{|l|}{ Marital status } \\
\hline Married & 96 & 114 & 0.285 \\
\hline Single & 3 & 1 & 0.231 \\
\hline Divorced & 1 & 0 & 0,125 \\
\hline \multicolumn{4}{|l|}{ Gravidity } \\
\hline gravida & 25 & 27 & 0.139 \\
\hline Paucigeste & 31 & 50 & 0.138 \\
\hline multigravida & 44 & 38 & 0.376 \\
\hline \multicolumn{4}{|l|}{ Parity } \\
\hline primipare & 30 & 41 & 0.086 \\
\hline few previous deliveries & 33 & 46 & 0.077 \\
\hline multiparous & 29 & 26 & 0.041 \\
\hline great multipare & 8 & 2 & \\
\hline Dysmenorrhea & 28 & 29 & 0.645 \\
\hline Genital infections & 19 & 17 & 0.567 \\
\hline \multicolumn{4}{|l|}{ Study level } \\
\hline graduate & 6 & 11 & 0.065 \\
\hline Secondary studies & 25 & 28 & \\
\hline Primary & 34 & 46 & \\
\hline Koranic & 6 & 0 & \\
\hline Illiterate & 29 & 30 & \\
\hline \multicolumn{4}{|l|}{ Residence } \\
\hline Dakar & 31 & 38 & 0.605 \\
\hline Suburbs & 69 & 76 & 0.499 \\
\hline Regions & 0 & 1 & 0.857 \\
\hline \multicolumn{4}{|l|}{ Previous contraception } \\
\hline IUD & 1 & 11 & \\
\hline implants & 8 & 11 & \\
\hline depo-provera & 14 & 14 & \\
\hline Pills & 13 & 13 & \\
\hline Any & 64 & 66 & \\
\hline \multicolumn{4}{|l|}{ Pregnancy } \\
\hline singleton & 88 & 104 & 0.565 \\
\hline twins & 12 & 11 & 0.723 \\
\hline \multirow{4}{*}{$\begin{array}{c}\text { Insertion } \\
\text { Post-placental } \\
\text { immediate postpartum } \\
\text { manual } \\
\text { instrumental }\end{array}$} & 58 & 115 & \\
\hline & 42 & 0 & \\
\hline & 58 & 29 & \\
\hline & 42 & 86 & \\
\hline
\end{tabular}


For the caesarean group these distances were respectively $28 \mathrm{~mm}$ and $3 \mathrm{~mm}$. During follow-up visits, the average distances of F-C-IUD and IUD were respectively $15.7 \mathrm{~mm}$ and $5.1 \mathrm{~mm}$ in the $3 \mathrm{rd}$ month and $16 \mathrm{~mm}$ and $5 \mathrm{~mm}$ that 6 th month for group 1.

For group 2 (vaginal delivery) there were $16.8 \mathrm{~mm}$ and $8.2 \mathrm{~mm}$ in the $3 \mathrm{rd}$ month and $17 \mathrm{~mm}$ and $9.3 \mathrm{~mm}$ in the 6th month. Most IUD was well placed and the 3rd month, 4 IUD had moved (into position isthmus) which 1 related to group 1 .

At the 6th month, 3 were Isthmic position and only concerned group 2 (AVB).

\subsection{Expulsion of the IUD}

Expulsions were 9 to 3 months of follow-up; 7 concerned the Group 2 and only 2 for the Group 1. It involved partial expulsion (IUD isthmian situation) and total expulsion. At 6 months follow-up, 3 cases of partial expulsion were noted and concerned only group 2 . This makes a total expulsion rate of $5.3 \%$, with $9.5 \%$ for group 2, and $1.8 \%$ for group 1 (Table 2 ).

\subsection{Side Effects and Failure of Method}

No cases of pregnancy or uterine perforation were recorded during this study.

The bleeding was found in $2.1 \%$ of group 2 and $1.8 \%$ of Group 1 . Regarding the increased of the menstrual flow, it was found in $29.6 \%$ and $25 \%$ for group 2 and group 1 . However, this difference was not statistically significant ( $\mathrm{p}=0.756$ ).

Cramps and pelvic pain were noted in $3.7 \%$ of patients in group 1 and only $2.6 \%$ for group 2 to 6 months of follow-up ( $p=0.590)$.

Leucorrhoea were found in $29.9 \%$ of $37.6 \%$ respectively for group 2 and group $1(\mathrm{p}=0.275)$. The vaginal sampling performed at 6 months of follow-up found $17.6 \%$ of infection in patients in group 2 , and $16.2 \%$ in group 1 . There was no significant difference between the two groups $(\mathrm{p}=0.575)$.

A significant difference was found in the perception of IUD strings ( $\mathrm{p}=$ 0.000). At 6 months follow-up they were found in $95.4 \%$ of group 2 and only $50.5 \%$ in group 1 (Table 2 ).

In the 6th month follow-up $42.8 \%$ of patients in the group 2 and $43.1 \%$ in group 1 had their diaper return.

The removal rate was very low of about $1 \%, 2$ patients, because of menorrhagia.

\section{Discussion}

Nine patients had lost $4.2 \%$ of all our patients. Our lost rates of view turn out to be less significant than those found in the litttérature [5] [6] [7]. Indeed Iverson et al., Found $25 \%$ of lost sight [8]. In the cohort of Levi only $50 \%$ had returned to visit the sixth week [9]. The common explanation of these losses views would be the low socioeconomic status of patients, which is a real obstacle in monitoring this contraceptive method. 
Table 2. Side effects and complications.

\begin{tabular}{ccccc}
\hline Side effects & group 2 & group 1 & Total (n=215) & \\
\hline $\begin{array}{c}\text { Explulsion } \\
\text { total }\end{array}$ & 7 & & & \\
partial & 3 & 1 & 8 & \\
& $9.5 \%$ & $1.8 \%$ & $5.3 \%$ & $(\mathrm{P}=0.028)$ \\
Abnormal menstrual flow & $11(26.2 \%)$ & $12(25.6 \%)$ & & $(\mathrm{P}=756)$ \\
bleeding & $1(1.1 \%)$ & $3(2.8 \%)$ & & $(\mathrm{P}=0.432)$. \\
pains & $2(2.3 \%)$ & $4(3.7 \%)$ & & $(\mathrm{P}=0.590)$. \\
Vaginal discharge & $26(29.9 \%)$ & $41(37.6 \%)$ & & $(\mathrm{P}=0.257)$. \\
infections & $36(17.6 \%)$ & $33(16.2 \%)$ & $69(33.5 \%)$ & $(\mathrm{P}=0.575)$. \\
Perforation & 0 & 0 & 0 & 0 \\
Pregnancy & 0 & 0 & 0 & 0 \\
Missing strings & $4(4.6 \%)$ & $54(49.5 \%)$ & & $(\mathrm{P}=0.000)$. \\
Lost & $5(5 \%)$ & $4(3.5 \%)$ & $9(4.2 \%)$ & $(\mathrm{P}=0.886)$ \\
\hline
\end{tabular}

Most recent studies agree that postpartum IUD exposed to a higher risk of eviction as the interval IUD. However, there is a wide variability in the reported rates ranging from $2 \%$ to $27 \%$ after vaginal delivery and from $0 \%$ to $20 \%$ after caesarean [6] [7] [10] [11] [12] [13].

At the first follow-up visit deportation of the total rate was $4.2 \%$, it was full and partial expulsion. These evictions concerned both cesareans and bass tracks. Partial expulsion were $3.2 \%$ for group 2 against $0.5 \%$ for group 1 , the completely expelled IUD represented $4.2 \%$ for group 2 against $0.5 \%$ for group 1 . At the last visit monitoring, evictions concerned only the group of vaginal delivery, it was partial expulsion or $1.5 \%$. Gaye et al. found an expulsion rate of $2.3 \%$ [1]. The Indian series of Halder et al. evaluated the evictions to $4 \%$ for IUD after vaginal delivery against $2 \%$ for IUD per-Caesarean [4]. Thiam et al. reported in its comparative study $3.5 \%$ of expulsion for the group of low assaults against $2 \%$ for cesareans [14]. Morrison et al. 1.8\% reported eviction in Kenya and $19.4 \%$ in Mali [15]. A study conducted in Turkey showed an expulsion rate of $12.3 \%$ of IUDs inserted in the immediate postpartum period. In the series by Levi and al., No eviction had been found until six months postpartum [16]. postpartum period is a high risk of expulsion due primarily to an enlarged uterine cavity source of great mobilté IUD. The insertion momment and the insertion technique are important for reducing this risk. Thus, several studies including ours have shown that post-placental expulsion causes less than other postpartum periods [10] [17]. In addition, it is determined that high IUD placed in the fundus reduces the expulsion rate [18]. The insertion depth of the IUD is evaluated by measuring the distance between the fundus and the horizontal leg and thus the distance between the endometrium and the horizontal leg of the IUD. Xu et al. reported values ranging between 16 and $99 \mathrm{~mm}$. For the same series, expulsions occurred for an average distance between the fundus and horizontal leg $43.4 \pm$ $19.9 \mathrm{~mm}$. At a distance of $38.1 \pm 15 \mathrm{~mm}$, no expulsion was reported [19]. In the 
study of Sharad et al. evictions occurred from an average distance of $12.2 \mathrm{~mm}$ between the endometrium and the IUD, this distance was $5.3 \mathrm{~mm}$ for the normally placed IUDs [18]. In our series of medium distances IUD F-29 mm and 28 $\mathrm{mm}$ respectively for Group 2 and 1, and mean C-IUD distances of $3.7 \mathrm{~mm}$ and 3 $\mathrm{mm}$ for group 2 and 1 respectively.

Irregular bleeding occurs in $10 \%$ to $15 \%$ of cases. in our study only $2.1 \%$ of group 2 and $1.8 \%$ of group 1 complained of bleeding which was much lower than in the literature [4] [7] [20] [21] [22] increased menstrual flow, she was seen in $29.6 \%$ of group 2 and $25 \%$ in group 1 . Nevertheless it remained lower than the values reported in the literature. The delivery path will influence the occurrence of these symptoms. The management of these bleeding and abnormal menstrual flowS sometimes requires the administration of NSAIDs and a hemostat. In our study all patients who experienced a Higham score between 100 and 150 or 150 suérieur benefited from treatment with NSAIDs and exacyl. The treatment was effective in most, though two patients had desired IUD removed or $1 \%, 3$ months and the other at 5 months. This rate was similar to that found in the study of Halder et al. 2\% for waterways and $1 \%$ for cesarean [4].

Uterine cramping up a complaint frequencies among IUD users they are due to an increase in pro-inflammatory PGE. These pains tend to fade over time, but may require drug therapy based NSAIDs [23]. In our study were reported in $3.6 \%$ of patients in group 1 and only $1.1 \%$ for group 2 in the 3 rd month. In the 6th month the rate was 3.7\% for Group 1 against $2.6 \%$ for group 2 .

The risk of infection after post-placental insertion is low, and randomized trials have not shown a difference of infection based on the insertion point. Leucorrhées were found in $29.9 \%$ and $37.6 \%$ for group 2 and group 1 to 6 months. The examination of vaginal secretions had regained $17.6 \%$ of infection in patients in group 2, and $16.2 \%$ for group 1 . Our rates are substantially higher compared to those found in the literature [1] [4] [5] [14]. The explanation is that a proportion not negligent of our patients had a history of recurrent infections genital 19\% in group 2 and 15\% in Group 1. All of these patients had received treatment with anti-infective a good clinical response. No IUD had been withdrawn because of infection (Table 3).

Table 3. Reasons to remove the IUD.

\begin{tabular}{ccccc}
\hline Withdrawal Patterns & Insertion Type & $\begin{array}{c}\text { Removing 3 } \\
\text { months }\end{array}$ & $\begin{array}{c}\text { Removing 6 } \\
\text { months }\end{array}$ & Total \\
\hline \multirow{2}{*}{ menorrhagia } & Vaginal route & 1 & 1 & 2 \\
Pain and cramps & Caesarean & 0 & 0 & 0 \\
& Vaginal route & 0 & 0 & 0 \\
partial expulsion & Caesarean & 0 & 0 & 0 \\
& Vaginal route & 3 & 1 & 4 \\
infections & Caesarean & 1 & 0 & 1 \\
& Vaginal route & 0 & 0 & 0 \\
Total & Caesarean & 0 & 0 & 0 \\
& Vaginal route & 3 & 2 & 5 \\
\hline
\end{tabular}


Non perception of IUD is a source of concern for patients but also for the health staff. Their research is part of the routine monitoring of an IUD. It is more common if the insertion is done in per-cesarean. At 6 months follow-up they were found in $95.4 \%$ of group 2 and only $50.5 \%$ in group 1 . In Levi and al study, they were found in $74 \%$ of patients [9]. In Hooda and al study, they were found in $55.1 \%$ for insertions made during caesarean versus $22.1 \%$ for vaginal insertions [5].

\section{Conclusion}

From the results of our study, we can say that IUD insertion in postpartum period is not a cons-indication in addition to being effective and safe. The risk of expulsion is minimal therefore acceptable whatever the mode of delivery and adverse effects are relatively rare.

\section{Conflicts of Interest}

The authors declare no conflicts of interest regarding the publication of this paper.

\section{References}

[1] Gueye, M., et al. (2013) Intrauterine Device Set up during Cesarean Section. Pilot Study Conducted at the Dakar University Hospital Center. Journal of Gynecology Obstetrics and Biology of Reproduction, 42, 585-590. https://doi.org/10.1016/j.jgyn.2013.06.003

[2] National Agency for Statistics and Demography (ANSD) (2017) Senegal: Demographic and Continuing Health Survey (EDS-Continue) 2016. ANSD et ICF, Rockville.

[3] Lopez, L.M., et al. (2015) Immediate Postpartum Insertion of Intrauterine Device for Contraception. Cochrane Database of Systematic Reviews, No. 6, CD003036. https://doi.org/10.1002/14651858.CD003036.pub3

[4] Halder, A., et al. (2016) A Prospective Study to Evaluate Vaginal Insertion and Intra-Cesarean Insertion of Post-Partum Intrauterine Contraceptive Device. The Journal of Obstetrics and Gynecology of India, 66, 35-41. https://doi.org/10.1007/s13224-014-0640-2

[5] Hooda, R. and Mann, S. (2016) Immediate Postpartum Intrauterine Contraceptive Device Insertions in Caesarean and Vaginal Deliveries: A Comparative Study of Follow-Up Outcomes. International Journal of Reproductive Medicine, 2016, Article ID: 7695847. https://doi.org/10.1155/2016/7695847

[6] Jatlaoui, T.C., et al. (2014) Postplacental Intrauterine Device Insertion at a Teaching Hospital. Contraception, 89, 528-533.

https://doi.org/10.1016/j.contraception.2013.10.008

[7] Levi, E.E., et al. (2015) Intrauterine Device Placement during Cesarean Delivery and Continued Use 6 Months Postpartum: A Randomized Controlled Trial. Obstetrics \& Gynecology, 126, 5-11. https://doi.org/10.1097/AOG.0000000000000882

[8] Iverson, R., Rindos, N. and Sonalkar, S. (2012) Immediate Postplacental IUD Placement after Cesarean and Vaginal Deliveries at an Academic Training Center. Contraception, 86, 173-186. https://doi.org/10.1016/j.contraception.2012.04.027 
[9] Levi, E. (2010) Transcesarean IUD Insertion: A Prospective Cohort Study. Contraception, 82, 183-216. https://doi.org/10.1016/j.contraception.2010.04.051

[10] Celen, S., et al. (2004) Clinical Outcomes of Early Postplacental Insertion of Intrauterine Contraceptive Devices. Contraception, 69, 279-282.

https://doi.org/10.1016/j.contraception.2003.12.004

[11] Chen, B.A., et al. (2010) Postplacental or Delayed Insertion of the Levonorgestrel Intrauterine Device after Vaginal Delivery: A Randomized Controlled Trial. Obstetrics \& Gynecology, 116, 1079-1087. https://doi.org/10.1097/AOG.0b013e3181f73fac

[12] Dahlke, J.D., et al. (2011) Postpartum Insertion of Levonorgestrel-Intrauterine System at Three Time Periods: A Prospective Randomized Pilot Study. Contraception, 84, 244-248. https://doi.org/10.1016/j.contraception.2011.01.007

[13] Whitaker, A.K., et al. (2014) Postplacental Insertion of the Levonorgestrel Intrauterine Device after Cesarean Delivery vs. Delayed Insertion: A Randomized Controlled Trial. Contraception, 89, 534-539.

https://doi.org/10.1016/j.contraception.2013.12.007

[14] Thiam, O.C., et al. (2014) The Intra-Uterine Device (IUD) of the Immediate Postpartum a Comparative Study between the Caesarean IUD and the IUD Inserted after a Natural Delivery. Clinical Obstetrics, Gynecology and Reproductive Medicine, 1, 87-92. https://doi.org/10.15761/COGRM.1000123

[15] Morrison, C., et al. (1996) Clinical Outcomes of Two Early Postpartum IUD Insertion Programs in Africa. Contraception, 53, 17-21.

https://doi.org/10.1016/0010-7824(95)00254-5

[16] Levi, E., et al. (2012) Immediate Postplacental IUD Insertion at Cesarean Delivery: A Prospective Cohort Study. Contraception, 86, 102-105.

https://doi.org/10.1016/j.contraception.2011.11.019

[17] Nelson, A.L., Chen, S. and Eden, R. (2009) Intraoperative Placement of the Copper T-380 Intrauterine Devices in Women Undergoing Elective Cesarean Delivery: A Pilot Study. Contraception, 80, 81-83.

https://doi.org/10.1016/j.contraception.2009.01.014

[18] Singh, S., et al. (2016) A Dedicated Postpartum Intrauterine Device Inserter: Pilot Experience and Proof of Concept. Global Health: Science and Practice, 4, 132-140. https://doi.org/10.9745/GHSP-D-15-00355

[19] Xu, J.X., et al. (1996) A Comparative Study of Two Techniques Used in Immediate Postplacental Insertion (IPPI) of the Copper T-380A IUD in Shanghai, People's Republic of China. Contraception, 54, 33-38. https://doi.org/10.1016/0010-7824(96)00117-5

[20] Goldstuck, N.D. and Steyn, P.S. (2013) Intrauterine Contraception after Cesarean Section and during Lactation: A Systematic Review. International Journal of Women's Health, 5, 811-818. https://doi.org/10.2147/IJWH.S53845

[21] Goldthwaite, L.M., et al. (2017) Postplacental Intrauterine Device Expulsion by 12 Weeks: A Prospective Cohort Study. American Journal of Obstetrics \& Gynecology, 217, 674.e1-674.e8. https://doi.org/10.1016/j.ajog.2017.08.001

[22] Haouas, N., et al. (2006) Intra-Vesical Migration of Intrauterine Device Complicated with Lithiasis. Journal of Gynecology Obstetrics and Biology of Reproduction, 35, 288-292. https://doi.org/10.1016/S0368-2315(06)78316-8

[23] Gronier, H., et al. (2012) Focus on Intrauterine Contraception in 15 Questions and Answers. Gynecology Obstetrics \& Fertility, 40, 37-42.

https://doi.org/10.1016/j.gyobfe.2011.07.022 